九州大学学術情報リポジトリ

Kyushu University Institutional Repository

\title{
Acoustic Emission and Cutting Resistance in Cutting of Solid Wood, MDF and Particleboard
}

Murase, Yasuhide

Laboratory of Wood Material Technology, Division of Biomaterial Science, Department of Forest and Forest Products Sciences, Faculty of Agriculture, Kyushu University

Matsumoto, Kenzo

Laboratory of Wood Material Technology, Division of Biomaterial Science, Department of Forest and Forest Products Sciences, Faculty of Agriculture, Kyushu University

Ohuchi, Takeshi

Laboratory of Woodworking, Department of Technology, Fukuoka University of Education

https://doi.org/10.5109/12862

出版情報：九州大学大学院農学研究院紀要. 53 (2)，pp.485-490，2008-10-28. Faculty of Agriculture, Kyushu University

バージョン :

権利関係 : 


\title{
Acoustic Emission and Cutting Resistance in Cutting of Solid Wood, MDF and Particleboard
}

\author{
Yasuhide MURASE*1, Kenzo MATSUMOTO*1 and Takeshi OHUCHI ${ }^{* 2}$ \\ Laboratory of Wood Material Technology, Division of Biomaterial Science, Department of \\ Forest and Forest Products Sciences, Faculty of Agriculture, Kyushu University, \\ Fukuoka 812-8581, Japanese \\ (Received JJune 27, 2008 and accepted July 16, 2008)
}

\begin{abstract}
In this study, to obtain basic knowledge on $\mathrm{AE}$ characteristics in the cutting process of wood and wood-based materials, the acoustic emission and cutting resistance in the cutting of solid wood, MDF and particleboard were examined.

The following main results were obtained :

(1) In the cutting of solid wood, with increasing slope angle of grain the $\mathrm{R}_{\mathrm{H}}$ showed an increasing tendency and the $R_{V}$ had a negative value with slight increase. The AE signals showed a rapid increase at slope angle range of 30 to 60 degree and then decreased or kept constant. It was found that the $\mathrm{AE}$ generation was closely linked to state of chip formation, compared with cutting resistances.

(2) In the cutting of MDF, with increasing slope angle from pressing face of board the $R_{\mathrm{H}}$ showed an increasing tendency and the $R_{v}$ had a negative value with slight increase. The AE signals also showed a rapid increase at slope angle range of 30 to 60 degree and then almost kept constant. It was found that the $\mathrm{AE}$ generation in cutting was closely linked to slope and orientation of fiber. Comparing with edge cutting, it was suggested that the values of cutting resistances and AEs in the cutting of only surface layer of MDF became more higher.

(3) In the cutting of $\mathrm{PB}$, the resistances showed irregular variations with time and AE was generated continuously. With increasing resin content of made board the $\mathrm{R}_{\mathrm{H}}$ showed an increasing tendency and the $\mathrm{AE}$ signals also increased. It was found that the $\mathrm{AE}$ generation in cutting of $\mathrm{PB}$ was complicatedly linked to cutting of particle and presence of adhesive.
\end{abstract}

\section{INTRODUCTION}

Acoustic emissions (AEs) refers to the elastic stress waves generated by the sudden release of energy in deforming or fracturing materials. Therefore, wood machining processes such as cutting and sanding all generate acoustic emission. The acoustic emissions generated in the wood machining process hold promise as a means to monitor tool wear, chip formation, surface roughness, and so on (Lemaster et al., 1982; Denaud et al., 2004).

In the previous studies, authors examined the $\mathrm{AE}$ characteristics in the veneer peeling process (Murase et al., 2004, 2005). The following results were obtained in the veneer peeling with a roller bar: (1) The AE level caused by compression of the roller bar was low, while that caused by cutting with the veneer knife was remarkably high. (2) Large-amplitude AE and the depth of the lathe check decreased as the compression and restraint increase in the roller bar settings. On the other hand, the following results were obtained in the veneer peeling with a nose bar: (1) The AE level caused by compression or friction of the nose bar was low, while that caused by cutting with the veneer knife was remarkably high. (2) Under variable nose bar openings, veneer thickness and

\footnotetext{
1 Laboratory of Wood Material Technology, Division of Biomaterial Science, Department of Forest and Forest Products Sciences, Faculty of Agriculture, Kyushu University, Japanese

${ }^{2}$ Laboratory of Woodworking, Department of Technology, Fukuoka University of Education, Japanese

* Corresponding author (E-mail: ymurase@agr.kyushu-u.ac.jp)
}

specimen temperature, AE generation was closely linked to the occurrence of lathe check. It was found from these results that the $\mathrm{AE}$ technique is promising for the monitoring of veneer quality in the peeling process.

Furthermore, authors examined the effects of cutting and clearance angles on acoustic emission and cutting resistance in 90-0 cutting, 0-90 cutting and medium density fiberboard (MDF) cutting ( Murase et al., 2007). The following results were obtained : (1) With increasing cutting angle, horizontal cutting resistance increase. On the other hand, The AE level increases and reaches a maximum at cutting angle of 40 or 50 degree, and then decreases. It is suggested that the variation of $\mathrm{AE}$ level is linked intimately to the process of chip formation. (2) With decreasing clearance angle, horizontal cutting resistance does not change very much and the AE level decreases. However, at clearance angle of 0 degree, horizontal cutting resistance increases remarkably and the AE level decrease continuously. It is suggested that the $\mathrm{AE}$ level caused by friction between clearance face of knife and workpiece is low.

In this study, to obtain basic knowledge on $\mathrm{AE}$ characteristics in the cutting process of wood and woodbased materials, the acoustic emission and cutting resistance in the cutting of solid wood (spruce), MDF and particleboard (PB) were examined.

\section{MATERIALS AND METHODS}

\section{Experimental apparatus}

The experimental apparatus shown in Figure 1 was used in this study. In this apparatus, the wood specimen 


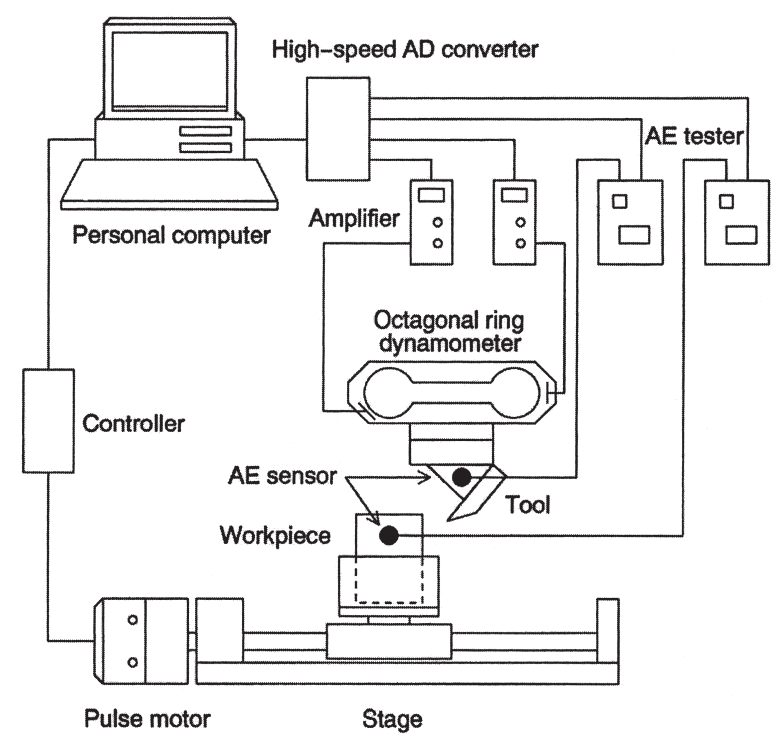

Fig. 1. Schematic diagram of the experimental apparatus.

was set on the stage driven by a pulse motor controlled with personal computer (PC). The cutting tool was mounted on a dynamometer. Cutting was carried out by moving a wood specimen forward to the cutting tool.

Two AE transducers (150 kHz resonant frequency) were used : one was mounted on the side face of the tool holder with a thermoplastic adhesive while the other was mounted on the side face of the workpiece with a rubber band, using silicon grease as the couplant between workpiece and $\mathrm{AE}$ transducer. In the experiment, the latter transducer was kept at a constant distance $(10 \mathrm{~mm})$ from the cutting line.

In measurement of AEs and cutting resistances during cutting, the output signals of the AE transducers or dynamometer were each amplified and then input simultaneously to a PC with a high speed A/D converter. For AEs, after the output signals were amplified by $50 \mathrm{~dB}$ and then $100 \mathrm{kHz}$ high-pass filtered, the average signals by half-wave rectification were input to the PC.

\section{Experimental conditions}

Cutting conditions are shown in Table 1. The tool was composed of high speed steel (SKH51). The cutting angle was constant 40 degree at clearance angle of 10 degree and the cutting speed was $0.5 \mathrm{~mm} / \mathrm{sec}$. The dimension of a workpiece was $30 \mathrm{~mm}$ (length) $\times 10 \mathrm{~mm}$ (width) $\times 50 \mathrm{~mm}$ (height). The depth of cut was varied at $0.1 \mathrm{~mm}$ and $0.3 \mathrm{~mm}$.

The detail of spruce specimen are shown in Table 2. The specimens used were the average moisture content

Table 1. Cutting conditions

\begin{tabular}{lc} 
Cutting tool & High-speed steel (SKH51) \\
Cutting speed (mm/sec) & 0.5 \\
Depth of cut (mm) & $0.1,0.3$ \\
Cutting angle (deg.) & 40 \\
Clearance angle (deg.) & 10 \\
Work dimension (mm) & $30 \times 10 \times 50$ \\
\hline
\end{tabular}

Table 2. Details of Spruce specimen

\begin{tabular}{lc}
\hline Specific gravity & 0.47 \\
Moisture content (\%) & 13.8 \\
Slope angle (deg.) & $0,15,30,45,60,75,90$ \\
\hline
\end{tabular}

Table 3. Details of MDF specimen

\begin{tabular}{lc}
\hline Specific gravity & 0.62 \\
Moisture content (\%) & 9.4 \\
Slope angle (deg.) & $0,15,30,45,60,75,90$
\end{tabular}

Table 4. Manufacturing conditions of particleboard

\begin{tabular}{|c|c|}
\hline Board size (mm) & $365 \times 255 \times 10$ \\
\hline Particle size (mesh) & under 24 \\
\hline Average moisture content of particles (\% & \%) 6.3 \\
\hline Traget board density $\left(\mathrm{g} / \mathrm{cm}^{3}\right)$ & 0.7 \\
\hline Adhesive $\quad$ Meramin-urea form & Meramin-urea formaldehyde resin \\
\hline Resin content (\%) & $6,8,10,12,14$ \\
\hline Pressing temperature $\left({ }^{\circ} \mathrm{C}\right)$ & 160 \\
\hline Pressing time (min) & 8 \\
\hline Thickness of distance bar (mm) & 10 \\
\hline
\end{tabular}

Table 5. Details of particleboard specimen

\begin{tabular}{lc}
\hline Resin content (\%) & $6,8,10,12,14$ \\
Specific gravity & $0.66,0.70,0.69,0.70,0.71$ \\
Moisture content (\%) & $9.0,9.2,8.8,8.3,9.2$
\end{tabular}

of $13.8 \%$, average specific gravity of 0.47 . The LT face ( $30 \mathrm{~mm} \times 10 \mathrm{~mm}$ ) of specimen was cut parallel to the grain. In experiments, the slope angle of grain was varied at $0,15,30,45,60,75$ and 90 degrees.

The detail of MDF specimen are shown in Table 3. The MDF specimens used were the average moisture content of $9.4 \%$, average specific gravity of 0.62 . The MDF specimens were cut from the block that 6 plies of a commercial MDF board (thickness: $9 \mathrm{~mm}$ ) were laminated using the adhesive of vinyl acetate resin. For cutting from the block, the cutting angles to the pressing face were varied at $0,15,30,45,60,75$ and 90 degrees. In the cutting of 0 degree, the center layer of MDF board was cut parallel to the pressing face.

The manufacturing conditions of particleboard and the detail of PB specimen are shown in Table 4 and 5 . The particles under screen of 24 mesh are prepared as a raw materials and a single layer $\mathrm{PB}$ are made with varied resin contents of $6,8,10,12,14 \%$ using melamine-urea formaldehyde adhesive. The moisture content and specific gravity of $\mathrm{PB}$ specimen tested are shown in Table 5 and the edge face was cut for PB specimen. In addition, MOE and MOR of PB were obtained.

\section{RESULTS AND DISCUSSION}

\section{Cutting of solid wood}

The typical variations of the resistances $\left(R_{H}\right.$; horizonta, $\mathrm{R}_{\mathrm{v}}$; vertical) acting on the tool and the AE signals at tool side (upper in each figure) and at workpiece side 
(lower in each figure) during cutting (from start to finish of cutting) of spruce wood are shown in Figure 2 and 3. In the figure 2 , the upper (a) is 0 degree of slope angle, the middle (b) is 15 degree and the lower (c) is 30 degree. In the figure 3 , the upper (a) is 45 degree of slope angle, the middle (b) is 60 degree and the lower (c) is 90 degree. Also, the resistance $\left(R_{V}\right)$ acting on a tool was represented as positive (+) when a tool was pushed up from the specimen.

For cutting of 0 degree of slope angle, the resistances showed large periodic variation with time. This occurrence of periodic variation was thought to be caused by chip formation of split type. Also, it was found that a large-amplitude AE was generated immediately after the peak in a periodic variation of resistance. For cuttings of 15 and 30 degree of slope angle, as the pitch in the split type chip become more shorter the resistances showed small but high frequency periodic variation with time, compared with 0 degree cutting. On the other hand, a remarkably large-amplitude AE generation was clearly observed.

For cutting of 45, 60 and 90 degree of slope angle, as the shear type chip were formed continuously the resistances showed relatively large value although a periodic

(a)

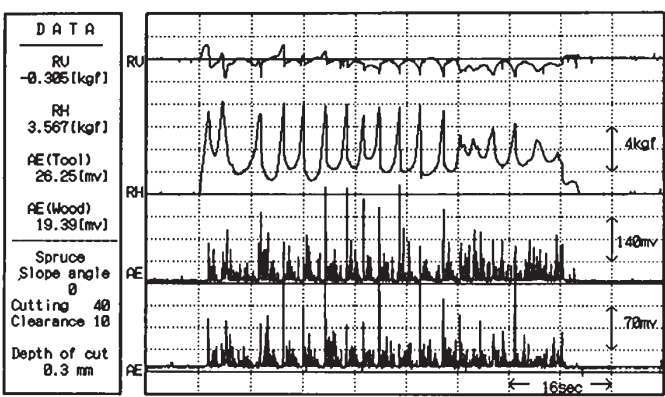

(b)

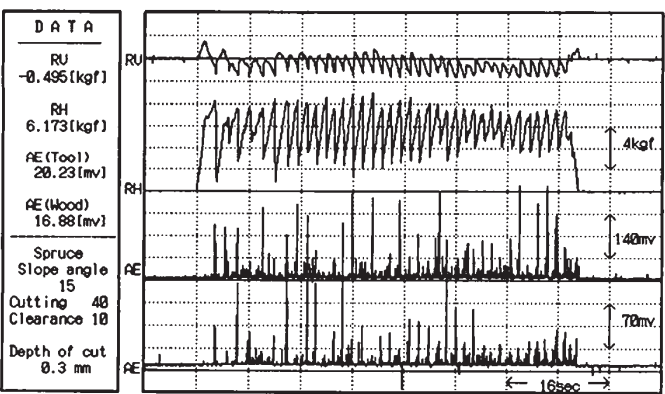

(c)

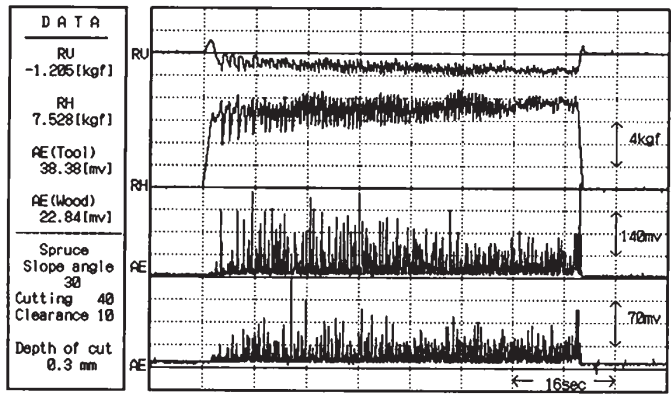

Fig. 2. Variations of cutting resistances and AEs during cutting of spruce wood (cutting angle $40^{\circ}$, clearance angle $10^{\circ}$, depth of cut $0.3 \mathrm{~mm}$ ).

Notes : (a) Slope angle of grain : $0^{\circ}$, (b) $15^{\circ}$, (c) $30^{\circ}$ (a)

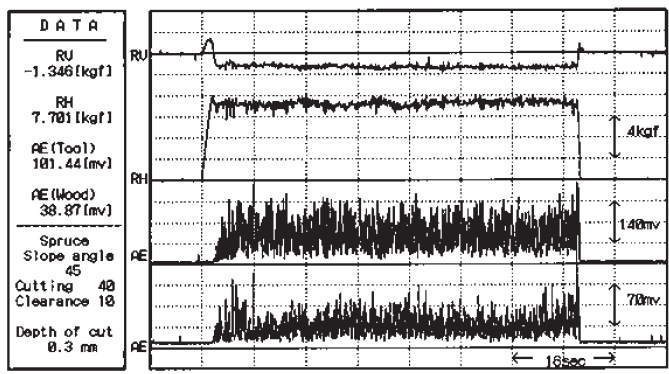

(b)

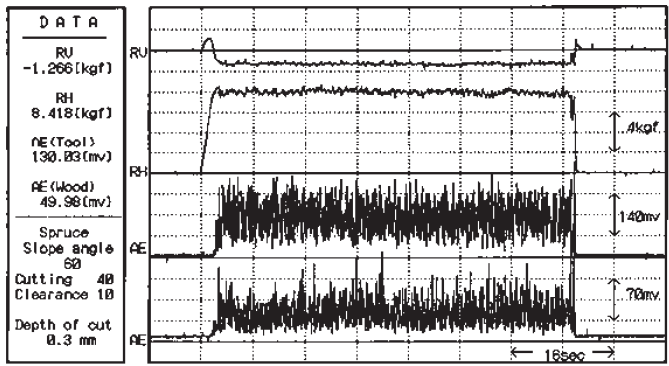

(c)

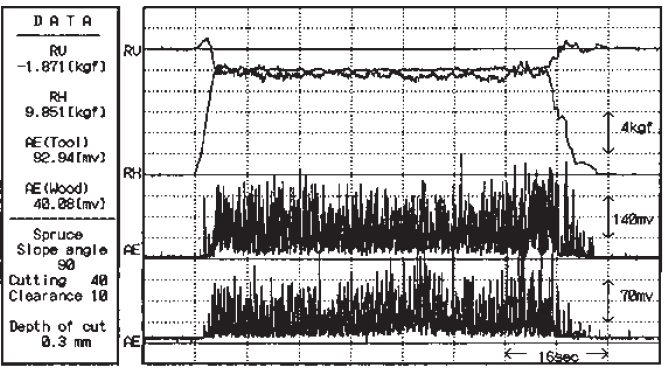

Fig. 3. Variations of cutting resistances and AEs during cutting of spruce wood (cutting angle $40^{\circ}$, clearance angle $10^{\circ}$, depth of cut $0.3 \mathrm{~mm}$ ).

Notes : (a) Slope angle of grain : $45^{\circ}$, (b) $60^{\circ}$, (c) $90^{\circ}$

variation was not clearly observed. On the other hand, a remarkably large-amplitude AE generation was observed continuously.

Relationships among cutting resistances $\left(R_{H}, R_{v}\right)$, AEs, chip length and slope angle of grain in the cutting of spruce wood at depth of cut of $0.1 \mathrm{~mm}$ and $0.3 \mathrm{~mm}$ are shown in Figure 4. Here, the measuring values are all the average values and $\mathrm{AE}$ values are the $\mathrm{AE}$ signals measured at tool side. With increasing slope angle of grain the $R_{H}$ showed an increasing tendency to 90-90 cutting of 90 degree and the $R_{\mathrm{v}}$ had a negative value with slight increase. The AE signals at tool side showed a rapid increase at slope angle range of 30 to 60 degree and then decreased or kept constant. On the other hand, by the variation of chip formation mechanism the chip length changed at slope angle range of 30 to 60 degree. From the above results, It was found that in solid wood cutting the $\mathrm{AE}$ generation was closely linked to state of chip formation, compared with cutting resistances.

\section{Cutting of MDF}

The typical variations of the resistances $\left(R_{H}, R_{V}\right)$ acting on the tool and the AE signals at tool side (upper in each figure) and at workpiece side (lower in each figure) during cutting of MDF are shown in Figure 5 and 6. In 


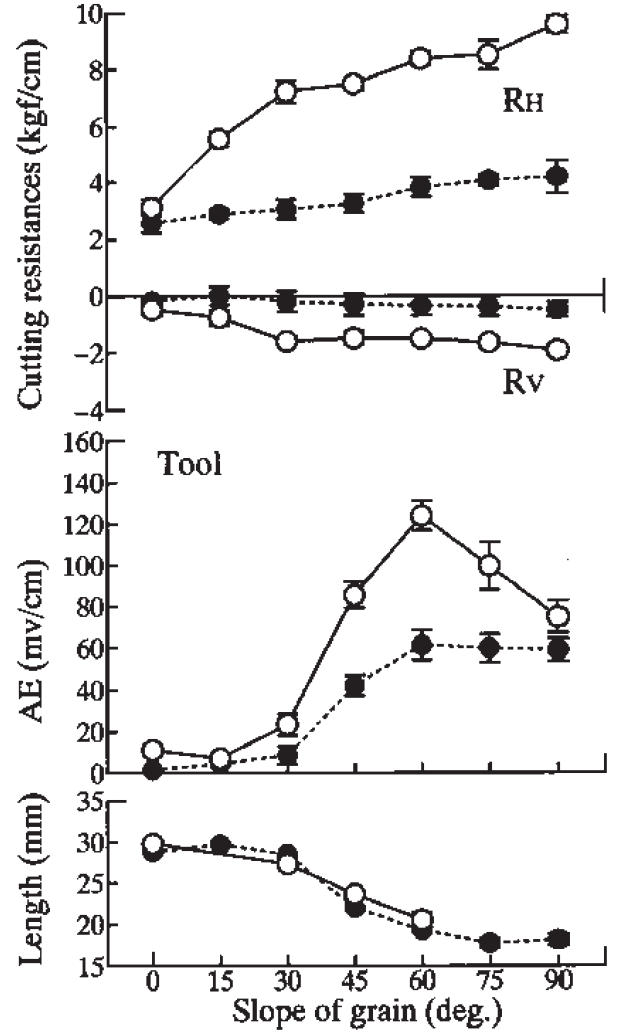

Fig. 4. Relationships among cutting resistances $\left(R_{H}, R_{V}\right)$, AEs, chip length and slope angle of grain in the cutting of spruce wood (cutting angle $40^{\circ}$, clearance angle $10^{\circ}$ ).

Legend : : depth of cut $0.1 \mathrm{~mm}, \bigcirc$ : depth of cut $0.3 \mathrm{~mm}$ Note $: R_{H}$ : Horizontal component of cutting resistance, $R_{V}$ : Vertical component of cutting resistance

the figure 5, the upper (a) is 0 degree of slope angle from pressing face of board, the middle (b) is 15 degree and the lower (c) is 30 degree. Also, in the figure 6, the upper (a) is 45 degree of slope angle from pressing face of board, the middle (b) is 60 degree and the lower (c) is 90 degree.

For cutting of 0 degree of slope angle that the center layer of MDF board was cut parallel to the pressing face, the resistances showed small value and little periodic variation with time, compared with solid wood cutting of 0 degree. On the other hand, it was observed that a relatively large-amplitude AE was generated continuously.

For cutting of 45, 60 and 90 degree of slope angle, It was clearly observed that the resistances showed a wave-like variation in the cutting process (from start to finish of cutting). This occurrence of wave-like variation was thought to be caused by the lamination of a commercial MDF board (thickness: $9 \mathrm{~mm}$ ). That is to say, by density distribution (high at surface layer and low at core layer of a board) of MDF the resistances showed a high value in the cutting of high density layer near the adhesion phase. On the other hand, It was found that a large-amplitude AE generation was observed in the cutting of low density layer (core layer of a board).

Relationships among cutting resistances $\left(R_{H}, R_{V}\right)$, AEs and slope angle from pressing face of board in the cutting of MDF at depth of cut of $0.1 \mathrm{~mm}$ and $0.3 \mathrm{~mm}$ are (a)

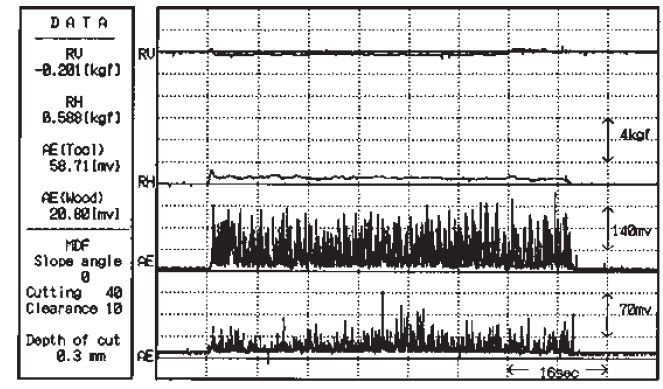

(b)

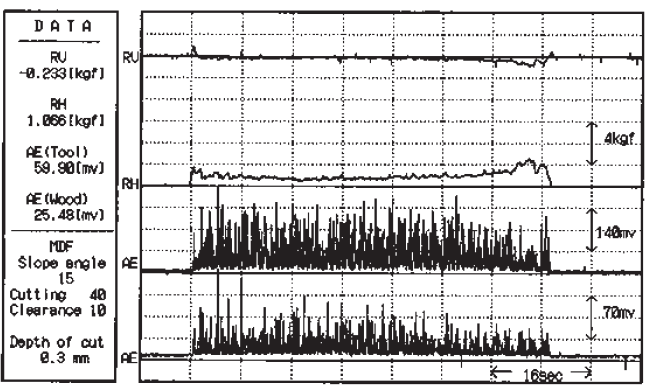

(c)

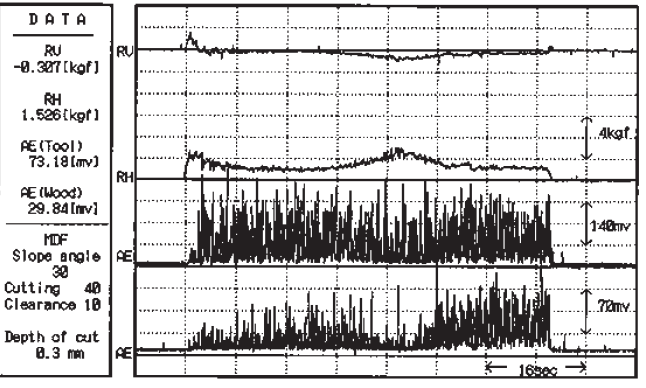

Fig. 5. Variations of cutting resistances and AEs during cutting of MDF (cutting angle $40^{\circ}$, clearance angle $10^{\circ}$, depth of cut $0.3 \mathrm{~mm}$ ).

Notes : (a) Slope angle from pressing face of board : $0^{\circ}$, (b) $15^{\circ}$, (c) $30^{\circ}$

shown in Figure 7. Here, the measuring values are all the average values in the cutting of low density layer (core layer of a board). With increasing slope angle from pressing face of board the $\mathrm{R}_{\mathrm{H}}$ showed an increasing tendency to 90 degree and the $R_{v}$ had a negative value with slight increase. The AE signals at tool side also showed a rapid increase at slope angle range of 30 to 60 degree and then almost kept constant. These variation tendencies of cutting resistances and AEs are similar to the variations of resistances and AEs with slope angle of grain in the cutting of solid wood. From the above results, It was found that the $\mathrm{AE}$ generation in cutting was closely linked to slope and orientation of fiber. Comparing with edge cutting of MDF that the high density layer at surface and the low density layer at core of a board were cut simultaneously, even for cutting of 90 degree of slope angle the values of cutting resistances and AEs are low. It was suggested that the values of cutting resistances and AEs in the cutting of only surface layer of MDF became more higher.

\section{Cutting of particleboard}

The typical variations of the resistances $\left(R_{\mathrm{H}}, R_{\mathrm{v}}\right)$ acting on the tool and the AE signals at tool side (upper in 
(a)

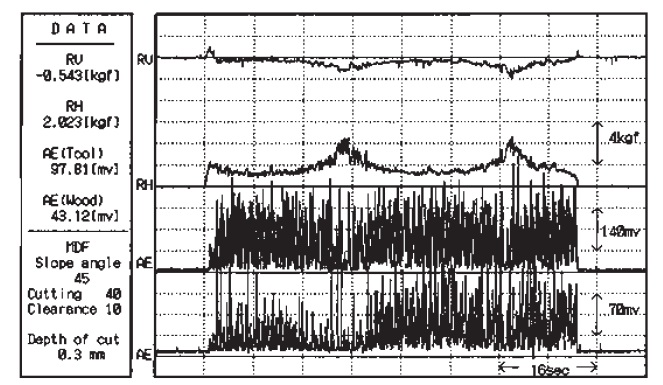

(b)

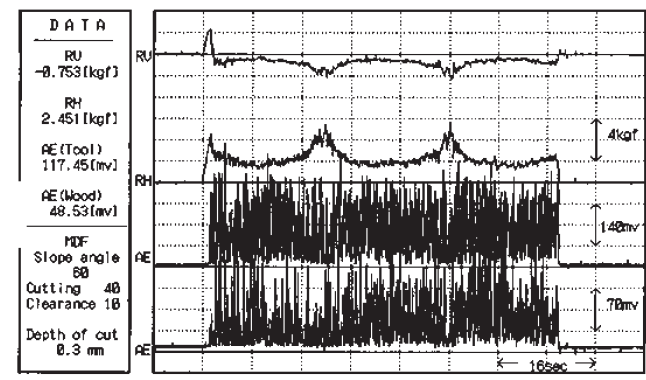

(c)

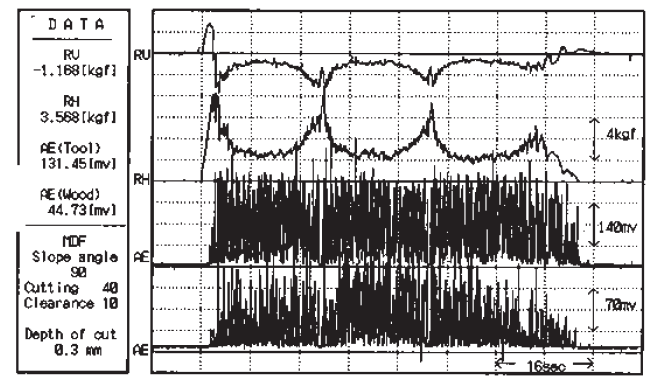

Fig. 6. Variations of cutting resistances and AEs during cutting of MDF (cutting angle $40^{\circ}$, clearance angle $10^{\circ}$, depth of cut $0.3 \mathrm{~mm})$.

Notes : (a) Slope angle from pressing face of board : $45^{\circ}$, (b) $60^{\circ}$, (c) $90^{\circ}$

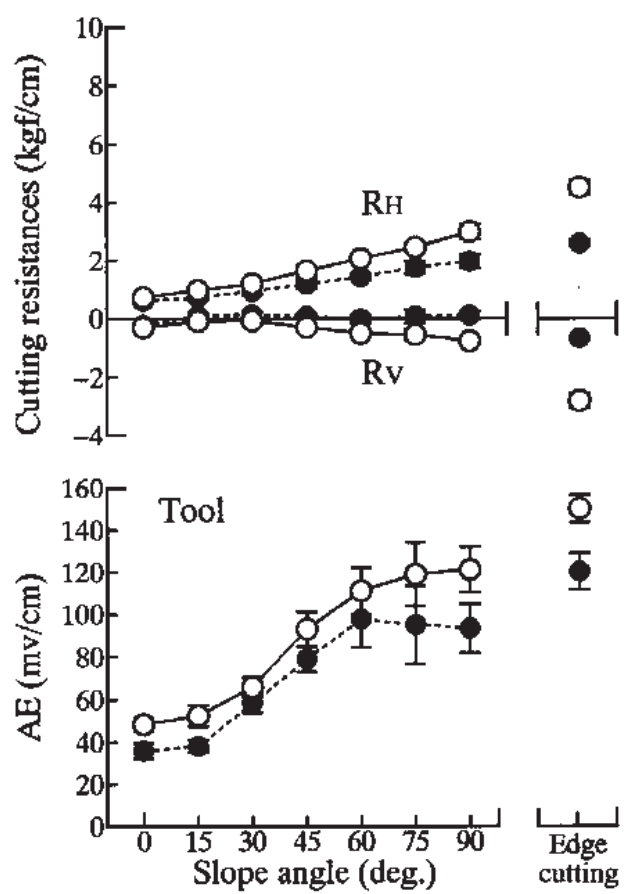

Fig. 7. Relationships among cutting resistances $\left(R_{H}, R_{V}\right), A E s$ and slope angle from pressing face of board in the cutting of MDF (cutting angle $40^{\circ}$, clearance angle $10^{\circ}$ )

Legend and Note : Same as Figure 4. each figure) and at workpiece side (lower in each figure) during cutting of particleboard are shown in Figure 8. In the figure, the upper (a) is $6 \%$ of resin content of made board, the middle (b) is $10 \%$ and the lower (c) is $14 \%$.

By the observation of cutting surface of $\mathrm{PB}$, It was suggested that the draw-out or drop-out of particle occured besides cutting of a particle and the draw-out or drop-out of particle decreased with increasing resin content. Therefore, for cutting of $\mathrm{PB}$, the resistances showed irregular variations with time. On the other hand, $\mathrm{AE}$ was generated continuously.

Relationships among cutting resistances $\left(\mathrm{R}_{\mathrm{H}}, \mathrm{R}_{\mathrm{v}}\right)$, AEs at tool side and workpiece side, MOE and MOR and resin content of made board in the cutting of PB at depth of cut of $0.1 \mathrm{~mm}$ and $0.3 \mathrm{~mm}$ are shown in Figure 9. With increasing resin content of made board the $R_{\mathrm{H}}$ showed an increasing tendency and the $\mathrm{AE}$ signals at tool and workpiece sides also increased. On the other hand, MOE and MOR showed increase tendency at resin content range of 6 to 10\% and then almost kept constant. From the above results, It was found that the $\mathrm{AE}$ generation in cutting of PB was complicatedly linked to cutting of particle and presence of adhesive.

(a)

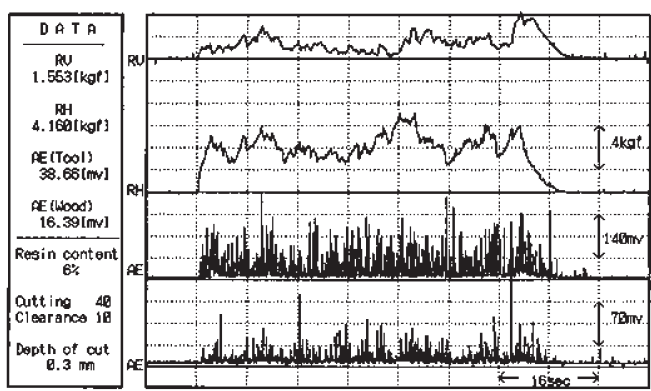

(b)

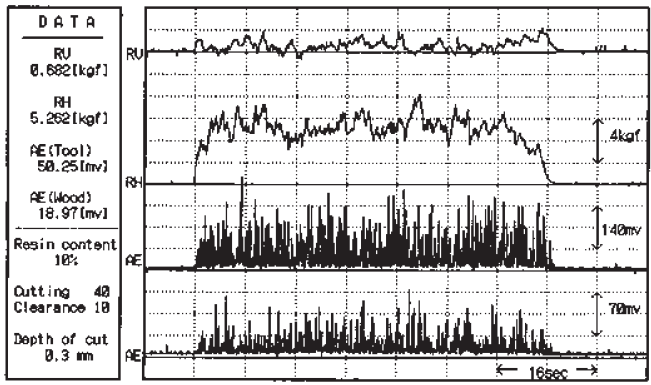

(c)

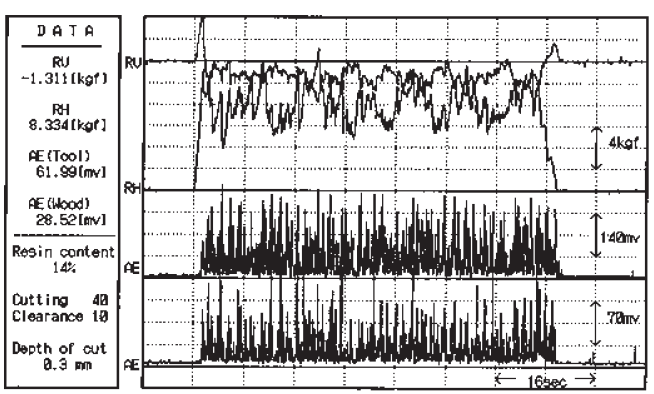

Fig. 8. Variations of cutting resistances and AEs during cutting of particleboard (cutting angle $40^{\circ}$, clearance angle $10^{\circ}$, depth of cut $0.3 \mathrm{~mm}$ ).

Notes : (a) Resin content : 6\%, (b) $10 \%$, (c) $14 \%$ 


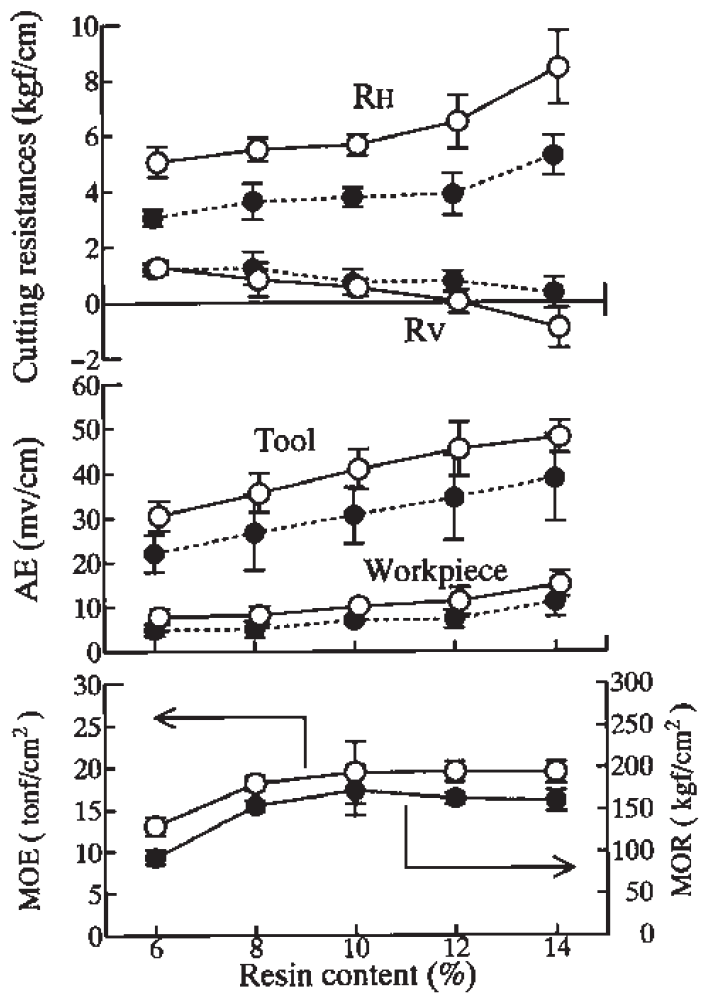

Fig. 9. Relationships among cutting resistances $\left(R_{H}, R_{v}\right)$, AEs, MOE , MOR and resin content in the cutting of particleboard (cutting angle $40^{\circ}$, clearance angle $10^{\circ}$ ). Legend and Note : Same as Figure 4.

\section{CONCLUSIONS}

In this study, to obtain basic knowledge on AE characteristics in the cutting process of wood and woodbased materials, the acoustic emission and cutting resistance in the cutting of solid wood, MDF and PB were examined.

The following main results were obtained :

(1) For 0, 15 and 30 degree of slope angle of solid wood cutting, the resistances showed clear periodic variation with time. This occurrence of periodic variation was thought to be caused by chip formation of split type. It was found that a large-amplitude $\mathrm{AE}$ was generated immediately after the peak in a periodic variation of resistance.

(2) For cutting of 45, 60 and 90 degree of slope angle, as the shear type chip were formed continuously the resistances showed relatively large value although a periodic variation was not clearly observed. A remarkably large-amplitude AE generation was observed continuously.

(3) With increasing slope angle of grain the $R_{H}$ showed an increasing tendency and the $R_{V}$ had a negative value with slight increase. The $\mathrm{AE}$ signals at tool side showed a rapid increase at slope angle range of 30 to 60 degree and then decreased or kept constant. It was found that in solid wood cutting the $\mathrm{AE}$ generation was closely linked to state of chip formation, compared with cutting resistances.

(4) For 0, 15 and 30 degree of slope angle from pressing face in MDF cutting, the resistances showed small value and little periodic variation with time. It was observed that a relatively large-amplitude AE was generated continuously.

(5) For cutting of 45, 60 and 90 degree of slope angle, It was clearly observed that the resistances showed a wave-like variation in the cutting process. By density distribution of MDF the resistances showed a high value in the cutting of high density layer near the adhesion phase. It was found that a large-amplitude AE generation was observed in the cutting of low density layer .

(6) With increasing slope angle from pressing face of board the $R_{H}$ showed an increasing tendency and the $R_{V}$ had a negative value with slight increase. The AE signals at tool side also showed a rapid increase at slope angle range of 30 to 60 degree and then almost kept constant. It was found that the $\mathrm{AE}$ generation in cutting was closely linked to slope and orientation of fiber. Comparing with edge cutting of MDF, It was suggested that the values of cutting resistances and AEs in the cutting of only surface layer of MDF became more higher.

(7) It was suggested that in the cutting of $\mathrm{PB}$ the draw-out or drop-out of particle occured besides cutting of a particle and the draw-out or drop-out of particle decreased with increasing resin content. For cutting of $\mathrm{PB}$, the resistances showed irregular variations with time and $\mathrm{AE}$ was generated continuously.

With increasing resin content of made board the $R_{\mathrm{H}}$ showed an increasing tendency and the AE signals at tool and workpiece sides also increased. It was found that the $\mathrm{AE}$ generation in cutting of $\mathrm{PB}$ was complicatedly linked to cutting of particle and presence of adhesive.

\section{REFERENCES}

Denaud L-E, Bleron L, Marchal R, Ratle A 2004 : Contribution to an on-line control of the peeling process: The vibro-acoustic approach. Proc. of $2^{\text {nd }}$ International symposium on Wood Machining, Vienna, Austria, pp. 175-183

Lemaster R. L., Klamecki B. E., Dornfeld D. A. 1982 : Analysis of acoustic emission in slow speed wood cutting. Wood Sci., 15 (2): 150-160

Murase Y, Nogami H, Ohuchi T 2004 : Acoustic emission characteristics in veneer peeling with a roller bar. Proc. of $2^{\text {nd }}$ International symposium on Wood Machining, Vienna, Austria, pp. 185-189

Murase Y, Nogami H, Ohuchi T 2005 : Acoustic emission characteristics in veneer peeling with a nose bar. Proc. of $17^{\text {th }}$ International Wood Machining Seminar, Rosenheim, Germany, pp. 310-318

Murase Y, Matsumoto K, Ohuchi T 2007 : Acoustic emission characteristics in wood cutting - Effects of cutting and clearance angles on acoustic emission and cutting resistance -. Proc. of $18^{\text {th }}$ International Wood Machining Seminar (Vol 2), Vancouver, Canada, pp. 81-88 